\title{
Educated Pass: engaging young males from low socio-economic status backgrounds with learning
}

Neil M Speirs

The underachievement of males, and their lack of engagement with academic work and formal achievement are well documented (Harris et al., 1993; Rudduck et al., 1996; Kessels \& Steinmayr, 2013). However, the lengths that males will go to in order to conceal any interest in or involvement with classwork are incredibly sophisticated. For example, Jackson et al. (2015) suggests that for some secondary school boys, the construct of 'laddishness' acts as a self-worth protection strategy. These extenuated efforts are made in order to preserve the individual's status within their peer group (Younger et al., 1996; Warrington et al., 1999). Males, in order to avoid social exclusion, act in line with peer-group norms which are very often in direct conflict with the ethos of participating constructively in the classroom environment (Skelton, 2001; Martino \& Pallotta-

Chiarolli, 2003; Tinklin, 2003). Educational achievement does not make adolescents more popular with peers (Coleman, 1961; Sebald, 1981; Landsheer et al., 1998).

Boys are often seen as 'troublesome' (Jones \& Myhill, 2004). Such stereotypes affect the perceptions and expectations that teachers have of pupils (Heyder \& Kessels, 2015). However, Bleach (1998, p.XV), pointed out that boys do not form a strict homogeneous grouping that are all "victims of the education system in terms of pedagogy and practice". Indeed, a more sophisticated analysis (Collins et al., 2000) generates a "which boys, which girls" approach to under-achievement. Poverty is the primary indicator for attainment for both males and females (Burnhill et al., 1990; Paterson, 1991; Sammons, 1995; Goodman \& Gregg, 2010), with the inequality of education attainment between the social classes growing since the late 1980 (Gillborn \& Mirza, 2000). As Lucey \& Walkerdine (2000, p. 37) underline: "mainly working-class boys continue to fail, while other, mainly middleclass boys, maintain their educational success". Connolly reminds us that:

$$
\begin{aligned}
& \text { It is not all young boys who are } \\
& \text { underachieving but rather certain } \\
& \text { groups of boys - particularly working } \\
& \text { class boys [...] and the problems they } \\
& \text { face are actually much more about } \\
& \text { social class and ethnicity than about } \\
& \text { gender per se. (Connolly, 2004, p. 232) }
\end{aligned}
$$

In order to promote participation and engagement with learning, I employ an approach that is credible to workingclass boys (Allen et al., 2015). My project, Educated Pass, draws on early notions of Olympism (Olympic Charter 2016). 'Blending sport with culture and education', this sophisticated approach is delivered through 'the educational value of good example'. Educated Pass works with under-achieving young males, from lower socio-economic status backgrounds, that play for local football clubs. The strong relationships that are built provide opportunities for the

89 EqualBITE Educated Pass: engaging young males from low socio-economic status backgrounds with learning 


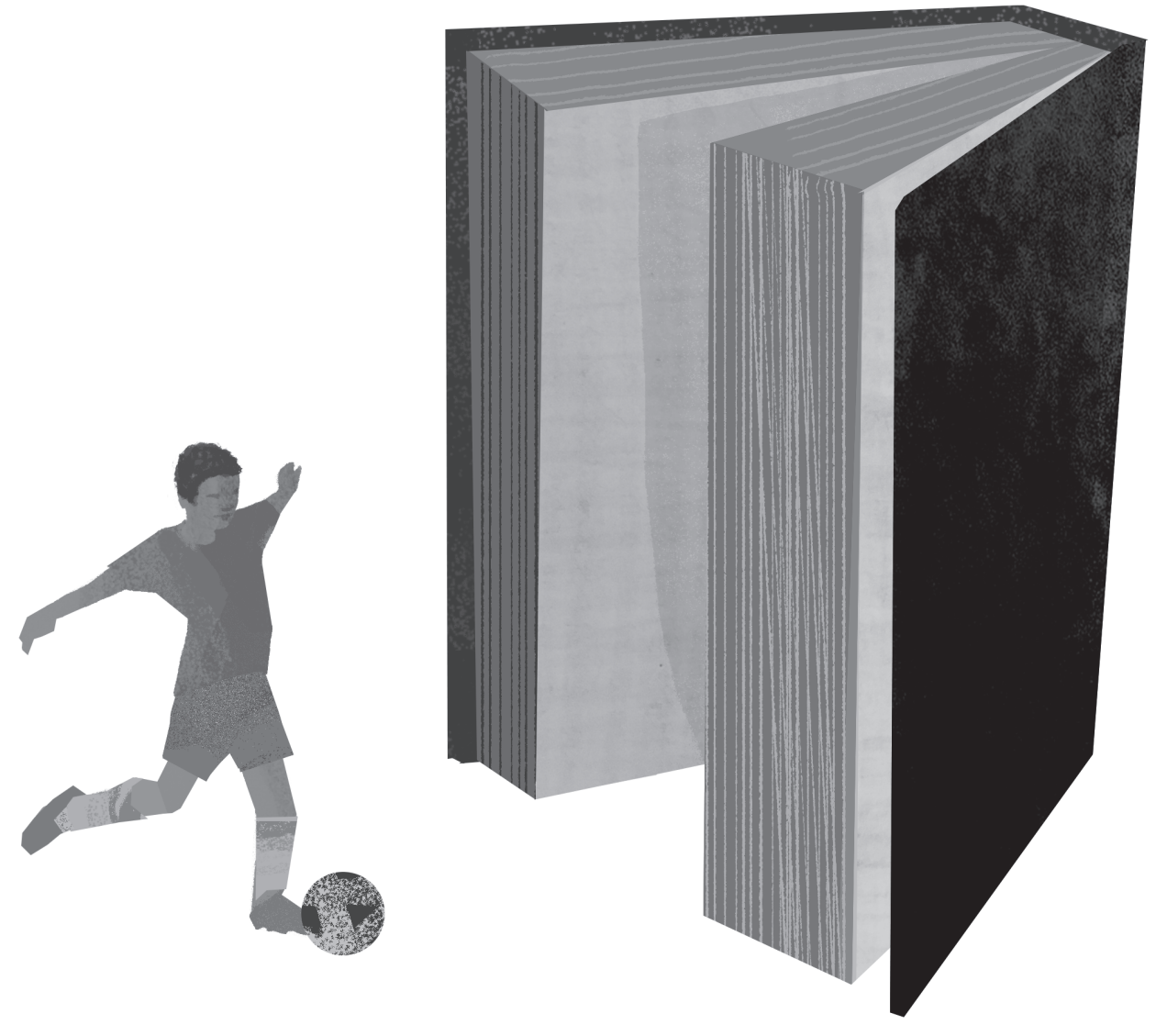

boys to develop bridging and linking social capital (Woolcock, 2001). The project has worked with some 1000 young males over the past ten years, in small wooden huts, old community centres and University of Edinburgh sporting facilities - normally under showers of rain and a gusty breeze. Spirits are never dampened though. Various partners have helped us to deliver the project, including the Scottish Youth Football Association, West Lothian College, Edinburgh College and the Centre for Sport and Exercise at the University of Edinburgh.

Educated Pass has a very close relationship with the University of Edinburgh football team. Team members and coaching staff act as positive role models, assisting the project delivery through 'the educational value of good example'.
You see, Educated Pass is about promoting taking part in life, making positive life choices. It's about spending time with communities as development takes place, not simply giving them new footballs and some gym kit. Sport is an enabler in all this; United Nations (2005) notes that "by its very nature sport is about participation. It is about inclusion and citizenship."

This all converges on the four capacities of the Curriculum for Excellence in Scotland: being successful, effective, responsible and confident learners. Capacities which the young boys that Educated Pass works with exhibit freely outside of the classroom. The challenge is to transfer this application and effort to the classroom to give their best on and off the pitch. 
We are aiming to open up a world of possibilities in order to challenge the situation in which "agents shape their aspirations according to concrete indices of the accessible and the inaccessible, of what is and is not 'for us"' (Bourdieu, 1990, p. 64).

We do not believe that it is reasonable or acceptable to allow the boys and their families to be wedded to life outcomes that are predicted by socio-economic status, or as Bourdieu continues, "inclining agents to 'cut their coats according to their cloth', and so to become the accomplices of the processes that tend to make the probable a reality" (Bourdieu, 1990, p. 65).

Research into those boys that have completed Educated Pass and subsequently left school shows a $98 \%$ positive destination (Educated Pass, 2015) compared with national figures in Scotland of 89\% for males and 92\% for females. The same report showed that participants in Educated Pass were almost 10 times more likely to study at degree level than to become a professional footballer. So, the message of positive life choices is starting to make its way through, highlighted by a parent of one of the boys who said:

If Educated Pass inspires just one child every year to think differently about their future, then it will have been worth it. Without it, horizons are narrower and aspirations less ambitious, and our society less diverse and more restricted.
We can probably summarise all of this with words from former French international footballer Eric Cantona when he said: "It is better to be a good man than a champion".

The ideas in this recipe will be useful for other groups within universities and communities who want to open up educational possibilities for young men from low socio-economic status backgrounds.

\section{Ingredients}

- A member of staff with a true love, appreciation and respect for education and sport, particularly football.

- Staff that hold an encyclopaedic knowledge of football.

- Experience playing in any team sport - at any level.

- A personalised pedagogical practice that fully understands the boys and their families.

- Access to quality university sporting facilities.

- The co-operation of student performance-level sportsmen and sportswomen and their managers.

- Community football teams for young males led by inspirational mums, dads and grandparents.

- Support from local colleges, local pro-teams and national sporting governing bodies. 
- A desire to positively influence the lives of young people and their families.

\section{Method}

1. It's vital to establish a sense of credibility with the boys and their families. This is achieved through the shared social interest of football and sport in general. According to FIFA (the governing body of association football), 1 in 25 people play football in some shape or form globally (FIFA, 2006). The message of participation in class will be lost, as it can be if delivered in the classroom, unless this credibility is established. Knowledge and understanding of the game is vital to form an initial rapport of trust. After all, football can unite people across generations as well as across class and race. We all love the gameregardless of where we come from or who we are. The message of taking part in class is delivered in the new classroom - the club house, under the approval of the new teacher - the head coach.

It's not a good idea to base interventions on assumptive gender stereotypes. However, if the individual, group or community that you are working with clearly express that they are indeed interested in an activity that just so happens to conform to such stereotypes -then it is OK to use this as the hook to engage them with their learning. In this case the boys and their families are part of local youth football teams - giving large amounts of their time and energy to what is their passion.

The program had a very positive impact on the team and boys. I was a coach, as well as a parent, and I noticed that this program provided more opportunities for the boys. Particularly, it enhanced their creativity in new ways they couldn't have imagined. (Coach/Parent)

2. It's important to bring relevancy to the curriculum; this involves linking any part of the curriculum to football and sport in general. A great way to do this is through inter-disciplinary learning which also helps the boys to understand how what they do now is linked to what they might do in the future. So, for example, this might involve a class based on human rights. Discussing this with 13-year-old boys and their families at 9pm at night isn't as tricky as you might think. The Pinochet regime, conflict in the former Yugoslavia or the civil war in Côte d'Ivoire may seem to be non-starters - but you couldn't be more wrong. You see Didier Drogba, the captain of Côte d'Ivoire stood against the conflict, Bosnian Pedrag Pasic opened a multi-ethnic football school in the heart of war-torn Sarajevo and 
Carlos Caszely said 'no to dictatorship' in Pinochet-ruled Chile. Before you know it, a critical appraisal of three devastating world events has taken place.

A second example would be the application and context of language learning. What if the boys had to be able to speak French because their favourite team were playing in Paris? They would need to get from the airport to the stadium, find out how to get to their seat. Buy a match programme, a drink and some food. After the match? Well they might meet some of the home fans and have a short discussion with them about the match. All of a sudden learning French is relevant. And if you want to work for UEFA, Europe's footballing governing body, well you'll need to be able to speak French or German as well as English. The fact you can do 100 keepy-uppies is irrelevant. (Keepy-uppy is a game where the aim is to juggle a football with any part of one's body, except the hands and arms, for as long as is possible. Each successful touch is numbered as one keepy-uppy.)

Educated Pass was extremely worthwhile and provided a perspective which was very interesting and relevant to all, as it linked sports and the importance of education as well as highlighting some important social issues. (Parent)
3. Next, we make sure that the experience is immersive and that it involves families and communities as well as the boys. This really follows the footballing idea of the home and away fixture. So we will visit the community where a particular club is based and deliver content. They will also visit us and experience the academic and sporting infrastructure that they will be unfamiliar with. But this goes on - local college partners will also welcome the boys and their families to campus so that all further and higher education is represented. And of course the final way to make the experience immersive is to have the support of a local pro-team that will allow their highlevel facilities to be used.

This selection of experiences in new and unfamiliar environments is facilitated by key partners. This could be role model student athletes, such as semi-professional student footballers or student athletes that have taken part in Olympic, world or Commonwealth competition. As well as university and college teaching staff, the coaching teams and sports scientists work with our students. Overall, the case for participating in class is richly illustrated by a number of places, people and facilities. The key is that the parents and families of the boys are also present and are able to 
witness the case for participating and to see that achievement and attainment in an educational setting have value and pay-off that may have thus far gone unnoticed, but also that it is relevant to their son, family and indeed wider community. Having support at home is vital for progression through school and beyond for the boys.

Educated Pass gave my son the confidence to get out and socialise more and to understand more about the working world. It also provided him with an idea of potential career paths, something to aim for and see what he could achieve. (Parent)
4. Our fourth step involves linking engaging and staying on at school with positive post-school destinations. We are clear in our presentation of the myriad of professions in sport that require the application of a vast selection of subject areas. For example, the marketing executive, the nutritionist, the physio, the lawyer, the administrator, the sports scientist or the business manager to name a few. But it is also important to illustrate opportunities outside of the world of sport, many of which could come from this list but used in a non-sporting environment. Ultimately we are looking for the boys to make positive life choices related to their education and training as well as their physical and mental health.

Educated Pass helped me to think that I want to go on and study health and science at uni or college when I leave school. Nobody in my family has done that before. (Player, holding midfielder)

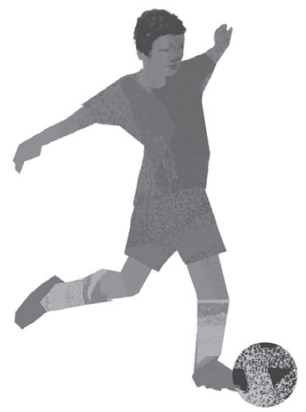

